\title{
Limbic System Participates in Mediating the Effects of General Anesthetics
}

\author{
Jingyi Ma ${ }^{1,2}$ and L Stan Leung*, 1,2,3 \\ 'Department of Physiology and Pharmacology, University of Western Ontario, London, ON, Canada; ${ }^{2}$ Department of Clinical Neurological \\ Sciences, University of Western Ontario, London, ON, Canada; ${ }^{3}$ Program in Neuroscience, University of Western Ontario, London, ON, Canada
}

\begin{abstract}
In a previous study, we reported that inactivation of the medial septum or the hippocampus by muscimol, a GABA $\mathrm{A}_{\mathrm{A}}$ receptor agonist, potentiated the effects of a general anesthetic. In this study, we further investigated whether other structures that are connected to the septohippocampal system are involved in mediating general anesthesia. In freely behaving rats, muscimol $(0.25 \mu \mathrm{g})$ or saline was infused intracerebrally into one of four areas - the supramammillary area (SUM), nucleus accumbens (NAC), ventral pallidum (VP), and ventral tegmental area (VTA) - and righting, pain, and EEG responses were recorded following either halothane or sodium pentobarbital, representing inhalational and injectable general anesthetic, respectively. The effect of halothane (2\%) or pentobarbital $(20 \mathrm{mg} / \mathrm{kg}$ i.p.) in abolishing the righting, pain response, or low-voltage neocortical activity was enhanced, and the initial behavioral hyperactivity (delirium) was reduced, after muscimol as compared to after saline infusion in SUM, NAC, VP, and VTA. EEGs in the hippocampus and the sensorimotor cortex following halothane or pentobarbital showed increased delta, and decreased hippocampal theta and gamma waves after muscimol infusion as compared to saline infusion in SUM, NAC, VP, and VTA. By contrast, infusion of muscimol in the median raphe increased locomotion and did not significantly alter the behavioral or EEG effects of halothane or pentobarbital. It is suggested that structures that activate the limbic cortices (MS, SUM, and VTA but not the median raphe) or mediate the output of the hippocampus (NAC and VP) normally participate in maintaining consciousness and inactivation of these structures potentiates the response to a general anesthetic.

Neuropsychopharmacology (2006) 3 I, I 177-| | 92. doi: I 0.1038/s..npp. 1300909; published online 5 October 2005
\end{abstract}

Keywords: supramammillary area; nucleus accumbens; ventral pallidum; ventral tegmental area; gamma rhythm; theta rhythm

\section{INTRODUCTION}

The limbic system is not generally recognized to mediate general anesthesia or consciousness. By contrast, consciousness, arousal, and attention are attributed to function of the thalamus and neocortex, with control through the brainstem (Devor and Zalkind, 2001; Jasper, 1949; Moruzzi and Magoun, 1949; Steriade, 2003). In a previous study (Ma et al, 2002), we demonstrated that the effects of a general anesthetic were potentiated by local inactivation of the medial septum or the hippocampus, parts of the limbic system, by a GABA-A receptor agonist muscimol.

The purpose of the present project is to further study the effects of inactivating other limbic structures. With the view of elucidating a limbic circuit that participates in general anesthesia, we focused on areas that project to and receive

\footnotetext{
*Correspondence: Dr LS Leung, Department of Physiology and Pharmacology, Medical Sciences Building, The University of Western Ontario, London, Ontario, Canada N6A 5Cl, Tel: +519 661 4367, Fax: + 519661 3827, E-mail: sleung@uwo.ca

Received 17 June 2005; revised II August 2005; accepted 22 August 2005

Online publication: 30 August 2005 at http://www.acnp.org/citations/ Npp083005050398/default.pdf
}

from the septohippocampal system. We selected three structures that project to the septohippocampal system: (1) the supramammillary area (SUM), an area in the hypothalamus that receives ascending inputs from the brainstem and projects glutamatergic and other inputs to the septum (Borhegyi et al, 1998; Kiss et al, 2000; Leranth and Vertes, 1999; Vertes and Martin, 1988) and hippocampus (Wyss et al, 1979); (2) the median raphe (MR), which projects serotonergic and nonserotonergic inputs to the septum and hippocampus (Vertes et al, 1999), and (3) the ventral tegmental area (VTA), which projects dopaminergic inputs to the nucleus accumbens (NAC), septal complex, hippocampus, and medial prefrontal cortex (Gasbarri et al, 1997; Swanson, 1982). Among the outputs of the hippocampus, we focused on the NAC, which in turn projects massively to the ventral pallidum (VP) (Groenewegen et al, 1987; Mogenson et al, 1993).

Structures of the mesolimbic dopaminergic system, including the NAC and the VTA, are known to modulate pain responses (Altier and Stewart, 1998; Gear et al, 1999; $\mathrm{Ma}$ and Han, 1991). Other than affecting anesthetic-induced behavioral hyperactivity (Irifune et al, 1997), NAC and VTA are not known to alter responses after a general anesthetic. In addition to assessing behavioral response to pain and 
righting, we recorded neocortical and hippocampal EEGs. Neocortical slow waves, or delta waves of $<4 \mathrm{~Hz}$ (Rampil, 1998; Steriade, 2003) and hippocampal theta $(4-10 \mathrm{~Hz})$ (MacIver et al, 1996; Vanderwolf, 1988) and gamma (30$100 \mathrm{~Hz}$ ) rhythms (Leung et al, 1982; Uchida et al, 2000) are known to be indicators of sleep-wake behaviors and levels of consciousness. Some of the results have been presented in an abstract form ( $\mathrm{Ma}$ et al, 2003).

\section{METHODS}

In male Long-Evans rats under pentobarbital anesthesia, two 23-gauge stainless steel guide cannulae were implanted for bilateral injections in the NAC (anterior (A) $1.5 \mathrm{~mm}$, lateral $(\mathrm{L}) \pm 1.2 \mathrm{~mm}$ and deep from skull surface (D) $6.9 \mathrm{~mm}$ ), VTA (P 5.3, L $\pm 1.0, \mathrm{D} 7.6$ ), SUM (P 4.6, L \pm 0.2 , $\mathrm{D}$ 6.7), VP (P 0.3, L $\pm 2.3, \mathrm{D} 7.8)$. One cannula was implanted in the MR (P 8.0, L 0.0, D 6.3). All coordinates were relative to bregma, with bregma and lambda on a horizontal plane (Paxinos and Watson, 1986). All rats were implanted bilaterally with $125 \mu \mathrm{m}$ stainless-steel wires in the dorsal hippocampus (P3-4.5, L $\pm 1.7-3.5, \mathrm{D} 2.9-3.4$ ) and frontal cortex (A 3.7, $\mathrm{L} \pm 3.2, \mathrm{D}$ 1.7). The wires were Tefloninsulated except at the cut tips and were used as recording electrodes, with a screw in the skull over the cerebellum serving as both the reference and the recording ground. After at least 7 days of recovery, a rat was habituated in a Plexiglas observation chamber of dimension $30 \times 30 \times 30 \mathrm{~cm}$, placed inside a fume hood. This fume hood shielded vision of the rat except in the front where the experimental always sat. Other than removing halothane, the fan of the fume hood also served to mask out auditory noise in the laboratory. Each rat served as its own control, and saline or muscimol was injected into one structure (NAC, VTA, SUM, VP, or MR) in a randomized order, with an interval of at least 4 days between experiments. Bilateral infusions were made manually, at a rate of $\sim 0.5 \mu \mathrm{l}$ per minute using a Hamilton syringe, through a 30 -gauge inner cannula. The muscimol doses were NAC (250 ng in $1 \mu \mathrm{l}), \mathrm{VP}$ $(250 \mathrm{ng} / 0.5 \mu \mathrm{l})$, SUM $(250 \mathrm{ng} / 0.5 \mu \mathrm{l})$ and median raphe $(250 \mathrm{ng} / 0.3 \mu \mathrm{l})$. Equal volume of vehicle (saline) was infused into the respective structure in control experiments. A general anesthetic was given 15-20 min after saline/muscimol infusion. Halothane concentration (typically 2\%) was determined by a specific vaporizer and carried by pure oxygen. The halothane was delivered by tubing into the bottom of the observation chamber at a flow rate of $81 / \mathrm{min}$, and allowed to leak through small holes at the top. Pentobarbital was injected at a normally subanesthetic dose of $20 \mathrm{mg} / \mathrm{kg}$ i.p.

Horizontal and vertical movements were quantified by the number of infrared beam interruptions in the observation chamber. Movements were assessed during habituation, baseline, and after anesthetic administration. The increase in locomotor activity was used to assess the behavioral excitation (delirium) induced by an anesthetic. Pain and righting responses of a rat were tested in room air, after $10 \mathrm{~min}$ of halothane exposure in the observation chamber, or $15 \mathrm{~min}$ after pentobarbital injection. For pain response, either the tail or the foot was pinched by an alligator clip. A positive response was indicated by move- ment of the body or movement of more than one limb. The pinch was applied periodically to the middle part of the tail, but not to the same part successively, and no permanent tissue damage resulted from the pinch. Righting was tested by placing the rat in a supine position, and a loss of response occurred if the rat could not right itself (ie, stand up on four limbs). Righting and loss of movements were clear behavioral measures and while most experiments were performed by a single experimenter, rating of loss of righting or pain response was confirmed by independent observers not knowing the history of treatment of the rats.

Separate experiments were conducted for EEG recordings. This was because the EEG cable that connected a rat interrupted infrared beams and obscured the movement measures. Hippocampal and neocortex EEGs were recorded before each anesthetic during one of two behaviors - walking and awake immobility. Walking was defined when the rat was active walking across the floor, and it was normally accompanied by a hippocampal theta rhythm. Awake immobility was defined as the state in which no movement of the head or limbs was observed, and it was normally accompanied by large slow irregular activity (with power mostly $<4 \mathrm{~Hz}$ ) in the hippocampus but low-voltage fast $(10-50 \mathrm{~Hz})$ activity in the neocortex (Leung et al, 1982; Stewart et al, 1984). EEG was recorded every minute, starting immediately after injection of pentobarbital $(20 \mathrm{mg} /$ $\mathrm{kg}$ i.p.) for $15 \mathrm{~min}$, or for $10 \mathrm{~min}$ after the introduction of halothane. Halothane $(5 \mathrm{ml})$ was absorbed onto paper towel in a glass container, and allowed to evaporate in the Plexiglas observation chamber (91 volume). At $10 \mathrm{~min}$ after administration, the percent of halothane in the chamber was estimated to be $\sim 2 \%$, based on the weight of halothane evaporated at the time. EEG was sampled at $200 \mathrm{~Hz}$, after high-pass filter at $0.3 \mathrm{~Hz}$. Every minute of EEG recorded was manually reviewed to exclude segments with artiefacts, and at least six segments of EEG ( $>30 \mathrm{~s}$ ), each segment of $5.12 \mathrm{~s}$ and 1024 points, were used for power spectral analysis (Leung et al, 1982). The power spectra were plotted in logarithmic units, with calibration that $1 \mathrm{mV}$ peak-to-peak sine wave $=6.15 \log$ units for channel 1 and $6.22 \log$ unit for channel 2. The peak of the power in the delta $(1-4 \mathrm{~Hz})$ range was measured during immobility before and after an anesthetic. The peak magnitude of the theta rhythm in the power spectrum was measured by the difference in logarithmic power between the peak within the range of $4-10 \mathrm{~Hz}$ and the onset of the peak at 3-6 Hz. Gamma power was measured by the mean integrated power in the gamma frequency band of $25-50 \mathrm{~Hz}$ (sum of power within the frequency band divided by the bandwidth).

At the end of experiments, the animals were killed under deep general anesthesia. The electrodes and the sites of cannula infusion were verified in $60-\mu \mathrm{m}$ frozen sections of the brain stained with thionin. Only data from rats with cannulae confirmed at the intended sites were used for analyses.

Unless noted otherwise, statistical comparison between two groups was performed using paired Wilcoxon test (twotailed). Data with multiple factors or levels were analyzed by one-way or two-way analysis of variance (ANOVA), followed by post hoc Newman-Keuls test. $p<0.05$ was considered to be statistically significant. 


\section{RESULTS}

\section{Effects of Inactivation of the SUM on Behavioral Excitation and Anesthesia}

Five rats were used for quantifying the spontaneous behavior in the observation cage for $30 \mathrm{~min}$ after SUM muscimol or saline infusion. Infusion of muscimol into SUM alone suppressed spontaneous locomotor behaviors. In saline-infused rats $(N=5)$, the number of horizontal beam interruptions (mean \pm standard error of the mean (SEM)) in consecutive 5 -min blocks when placed into the observation chamber were $1025 \pm 143,903 \pm 120,742 \pm 137$, $366 \pm 75,437 \pm 107$, and $432 \pm 135$. In contrast, muscimolinfused rats showed much smaller number of beam interruptions measured consecutively as $86 \pm 72,105 \pm 75$, $159 \pm 92,47 \pm 35,85 \pm 57$, and $19 \pm 13$ in 5 -min blocks. The total number of movements in $30 \mathrm{~min}$ was significantly different between saline- and muscimol-infused rats $(z=2.02, p<0.05$, Wilcoxon signed rank test). However, pain and righting responses were not affected by SUM muscimol (or saline) infusion alone in any rat (data not shown). Six rats were given $2 \%$ halothane after bilaterally infusion with muscimol $(250 \mathrm{ng} / 1 \mu \mathrm{l})$ or saline $(1 \mu \mathrm{l})$ into the SUM. After halothane administration, saline-infused rats showed a significant increase in locomotion measured as horizontal beam interruptions $\left(\mathrm{F}_{(1,5)}=7.11, p<0.05\right.$, twoway ANOVA from 1 to $6 \mathrm{~min}$, Figure 1c) while muscimolinfused rats did not show a significant increase in locomotion ( $p>0.05$, two-way ANOVA). Group difference between saline- and muscimol-infused rats was only significant at $5 \mathrm{~min}$ after halothane. At $10 \mathrm{~min}$ after halothane, the rat was taken out of the chamber and placed in a supine position for the testing of righting, tail-pinch, and foot-pinch responses. Compared to saline infusions, muscimol infusions in the SUM significantly prolonged the duration of the loss in righting reflex, tail-pinch, and footpinch responses $(z=2.20, p<0.05$, respectively, Wilcoxon signed rank test, Figure 1a).

Six other rats were used for muscimol/saline infusions in SUM followed by pentobarbital injection $(20 \mathrm{mg} / \mathrm{kg}$, i.p.). Saline-infused rats increased locomotion at 1-4 min after pentobarbital $\left(\mathrm{F}_{(1,5)}=52.81, p<0.01\right.$, two-way ANOVA, Figure 1d). In contrast, muscimol infusions in SUM significantly suppressed the increase in locomotion induced by pentobarbital as compared to baseline recording or saline-infused rats (Figure 1d). At $15 \mathrm{~min}$ after injection of pentobarbital, rats with saline infused into the SUM did not lose response to righting, tail pinch, or foot pinch. Muscimol-infused rats significantly increased the duration of lost response to righting, tail-pinch and foot-pinch, as compared to saline-infused rats $(z=2.20, p<0.05$, respectively, Wilcoxon signed rank test, Figure $1 \mathrm{~b}$ ).

\section{Effects of VTA Muscimol on Behavioral Excitation and Anesthesia}

Spontaneous behaviors were obviously decreased following VTA muscimol infusions before introduction of halothane or pentobarbital (not shown). Muscimol infusion alone, however, did not induce a loss of pain or righting reflex in any rat. As measured by automated beam interruptions, rats with muscimol infused into the VTA showed significantly lower locomotion at 1-4 min after halothane, as compared to VTA saline-infused rats $\left(\mathrm{F}_{(1,6)}=12.64, p<0.05\right.$, two-way ANOVA, Figure 2c). The duration of lost response to tail pinch, foot pinch and righting following $2 \%$ halothane was significantly enhanced by infusion of muscimol into the VTA, as compared to saline infusion $(z=2.52, p<0.05$, respectively, Wilcoxon signed rank test, Figure 2a).

VTA muscimol infusion also significantly suppressed pentobarbital-induced behavioral hyperactivity at $1-5 \mathrm{~min}$ compared to VTA saline infusions $\left(\mathrm{F}_{(1,6)}=72.11, p=0.0001\right.$, Figure $2 \mathrm{~d}$ ). After pentobarbital, muscimol-infused rats, as compared to saline-infused rats, had significantly prolonged loss of the foot or tail pinch response as well as the righting reflex $(z=2.20$, respectively, $p<0.05$, Wilcoxon signed rank test, Figure 2b).

\section{Effects of Accumbens-Muscimol on Behavioral Excitation and Anesthesia}

The infusion of muscimol (250 ng) alone in the NAC suppressed spontaneous behaviors, but did not induce a loss of pain response or righting reflex. However, when halothane was introduced, the muscimol (250 ng) infused rats showed a significantly reduced locomotion, as compared to saline-infused ratss $\left(\mathrm{F}_{(1,6)}=6.29, p<0.05\right.$, two-way ANOVA, Figure $3 \mathrm{c}$ ). Infusion of a higher dose of muscimol $(0.5-1 \mu \mathrm{g})$ into the NAC was usually fatal, for unknown reasons (electrical or behavioral seizures were not detected), and thus these doses were not used. Compared to saline infusions, muscimol infusion into the NAC significantly enhanced the anesthetic effects of halothane as indicated by a prolonged loss of tail pinch and righting reflex $(z=2.20$, $p<0.05$, respectively, Wilcoxon signed rank test; Figure 3a). Foot pinch was not performed in this experiment.

Muscimol significantly suppressed the increase in locomotion induced at 1-5 min after i.p. injection of pentobarbital $\left(\mathrm{F}_{(1,5)}=11.97, p<0.05\right.$; Figure 3d). After pentobarbital injection, muscimol-infused rats showed a remarkable increase in the duration of lost foot/paw pinch responses and righting reflex $(z=2.20, p<0.05$, respectively, Wilcoxon signed rank test, Figure $3 \mathrm{~b}$ ).

\section{Effects of VP Muscimol on Behavioral Excitation and Anesthesia}

Spontaneous behaviors, but not pain response or righting reflex, were suppressed by muscimol (250 ng) infusion alone in the VP. The animals could still stand up, but showed little spontaneous movements after muscimol infusion.

Compared to saline infusion, muscimol infusion in the VP significantly suppressed behavioral hyperactivity at 14 min following halothane $\left(\mathrm{F}_{(1,6)}=12.04 ; p<0.05\right.$, two-way ANOVA; Figure 4c). Also, muscimol compared to saline infusion in the VP significantly $(p<0.01$, Wilcoxon signed rank test) prolonged the duration of loss of tail pain, foot pain and righting response (Figure 4a).

Pentobarbital-induced increase in locomotion (1-4 min after injection) was significantly suppressed by muscimol compared to saline infusion into the VP $\left(\mathrm{F}_{(1,6)}=6.76\right.$, $p<0.05$, two-way ANOVA, Figure $4 \mathrm{~d}$ ). VP infusion of muscimol, compared to saline infusion, significantly 


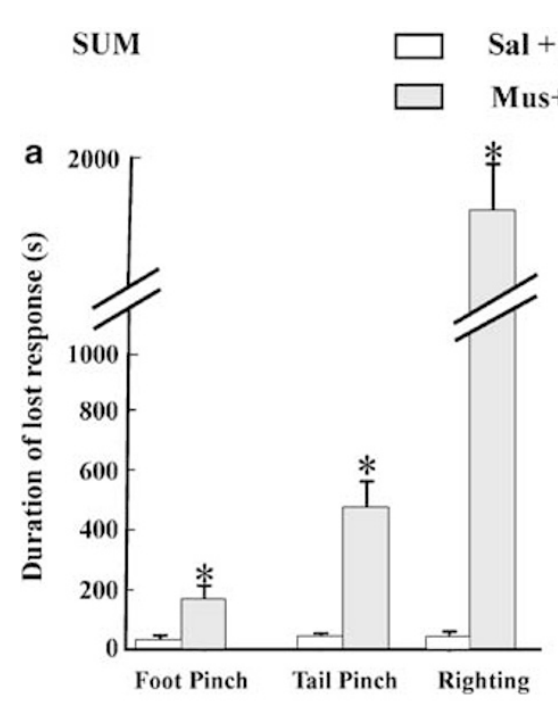

$$
\text { Sal + Halothane }(n=6) \quad \cdots \cdot \bullet \cdot-\cdot
$$$$
\text { Mus+Halothane }(n=6)
$$
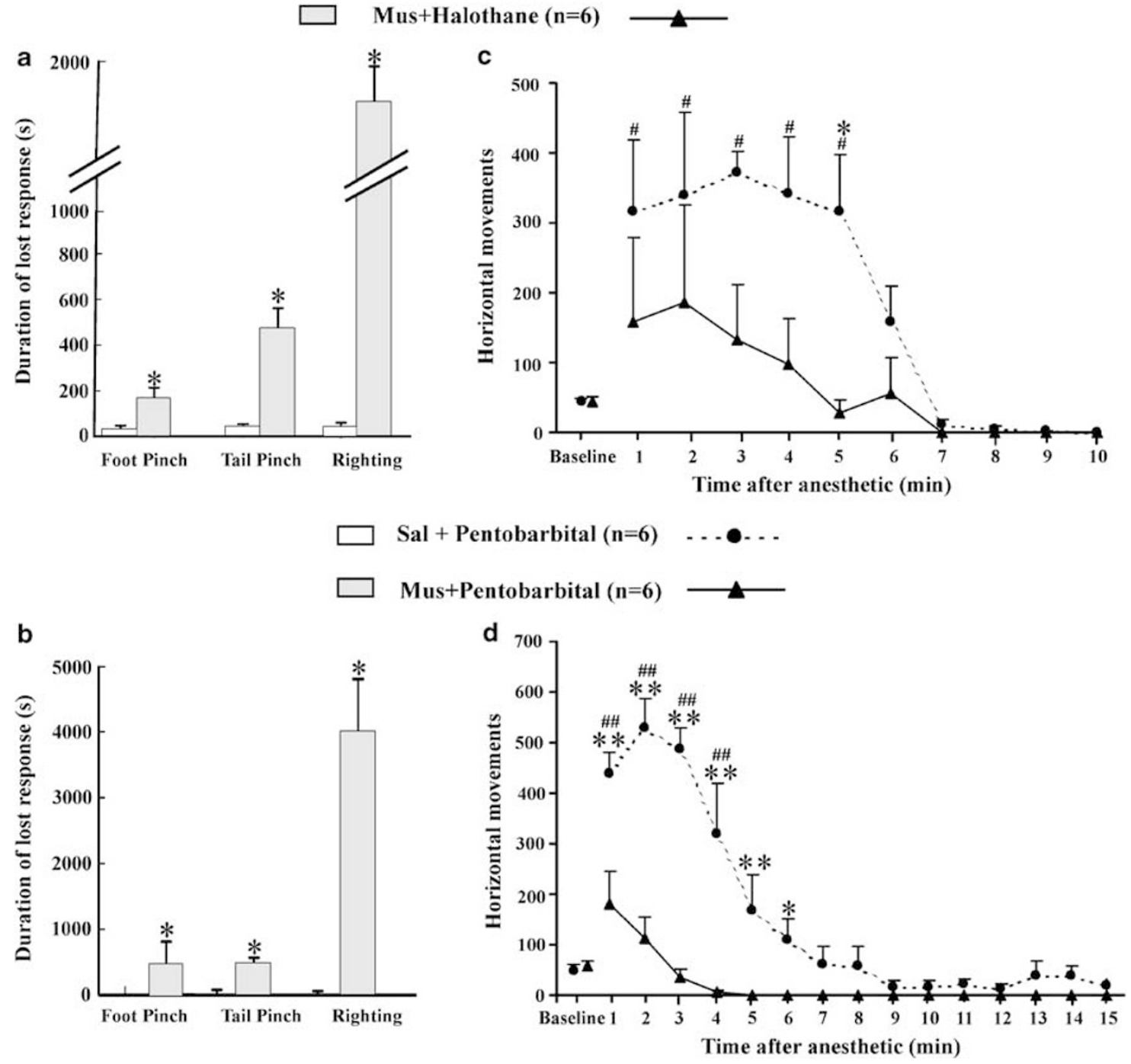

Figure I Inactivation of the supramammillary area (SUM) by muscimol infusion abolished behavioral excitation and prolonged anesthesia induced by halothane ( $a$ and $c$ ) or by pentobarbital ( $b$ and d). Rats were infused, in an order-randomized design, with saline (Sal) or muscimol (Mus) bilaterally into the SUM, and horizontal movements were quantified by the number of infrared beam interruptions in an observation chamber. (a) Duration of loss in the footor tail-pinch response or righting reflex (mean plus one standard error of the mean (SEM)) was prolonged by muscimol (Mus) as compared to control saline (Sal) infusion. Tests were performed in room air after 10 min exposure to $2 \%$ halothane. (c) Horizontal movements indicated by mean plus SEM of number of infrared beam interruptions during baseline (symbols shifted laterally for non-overlap) and after introducing halothane into the observation chamber. Baseline value was the average number of beam interruptions over 10 min after at least 20 min habituation in the chamber. Control rats showed an increase in horizontal movements (beam interruptions), which was significantly larger than that in muscimol-infused rats. (b) Duration of loss in the foot- or tail-pinch response or righting reflex (mean plus one SEM) was prolonged by muscimol as compared to saline infusion. (d) Control rats showed an increase in the number of infrared beam interruptions after sodium pentobarbital $(20 \mathrm{mg} / \mathrm{kg}$ i.p.), which was significantly larger than those after pentobarbital in muscimolinfused rats. * $p<0.05$; ** $p<0.01$ : difference between groups using paired Wilcoxon test (panels a and b), or using Newman-Keuls test after repeated measure ANOVA (panels $c$ and d). ${ }^{\#}<<0.05 ;{ }^{\# \#} p<0.01$ : difference from baseline using Newman-Keuls test after a significant repeated measure ANOVA.

prolonged the duration of lost response after pentobarbital, for the foot/tail pinch response and the righting response $(z=2.37, p<0.05$, respectively, Wilcoxon signed rank test, Figure $4 \mathrm{~b})$.

\section{Effects of MR Muscimol on Behavioral Excitation and Anesthesia}

In contrast to infusion into the nuclei described above, muscimol (250 ng) infusion into MR induced spontaneous behavioral hyperactivity as reported before (Sainati and Lorens, 1982; Shim et al, 1997). Pain response and righting reflex were intact after infusion of muscimol alone in the MR. Horizontal movements after halothane in muscimolinfused rats were higher than those after halothane in saline-infused rats $\left(\mathrm{F}_{(10,50)}=2.71 ; p<0.01\right.$; two-way ANOVA; Figure 5c). There was no statistical difference between muscimol- and saline-infused rats in the duration of lost response to foot pinch, tail pinch, or righting $(z=1.75$; $p=0.08$, respectively, Wilcoxon signed rank test, Figure $5 \mathrm{a}$ ), 
.......

Mus+Halothane $(n=7)$
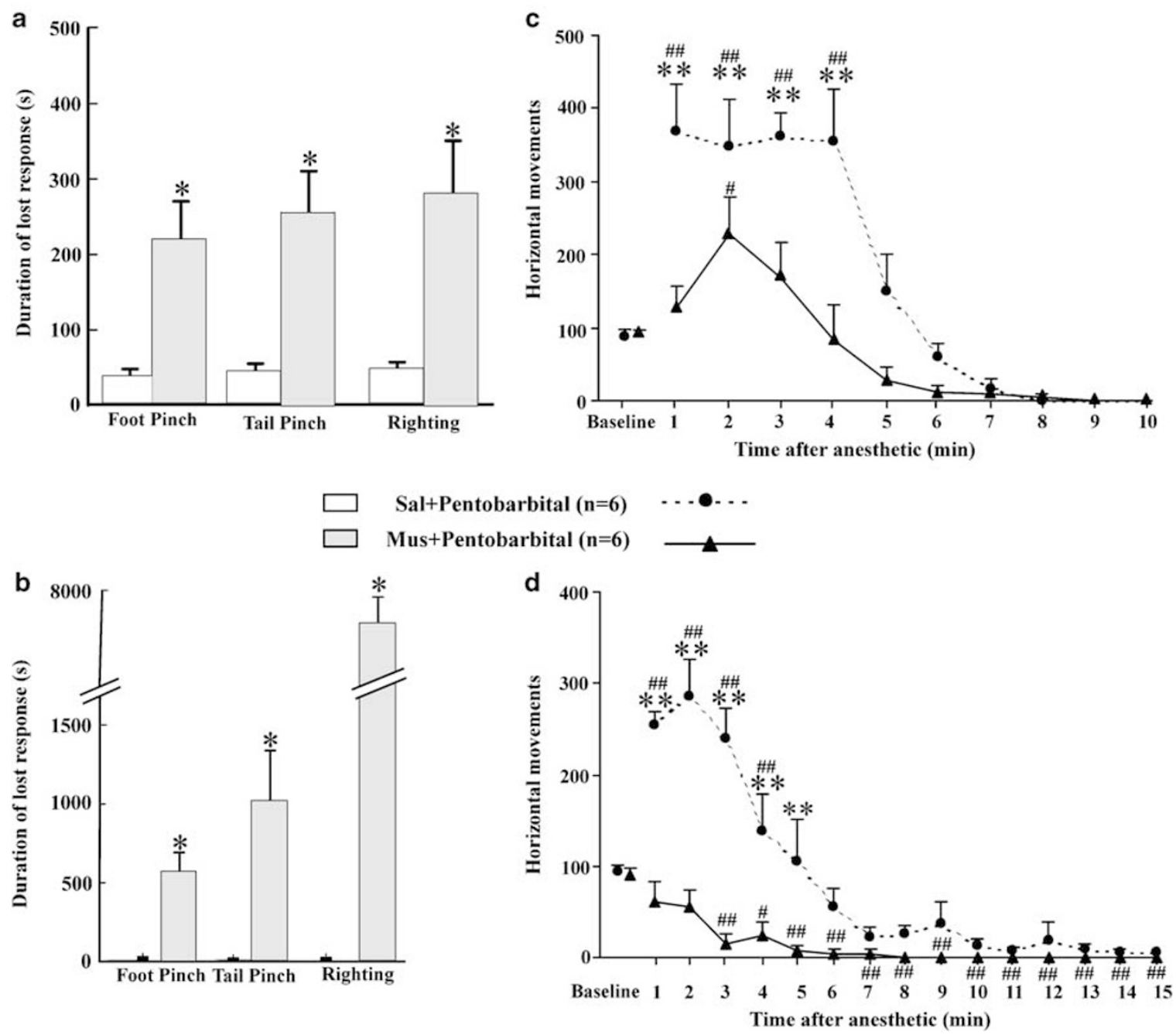

Figure 2 Inactivation of ventral tegmental area (VTA) by muscimol infusion prolonged the duration of lost pain and righting responses (a and b) and reduced horizontal movements ( $c$ and $d$ ) induced by halothane $(a, c)$ or pentobarbital $(b, d)$. Layout and symbols as in Figure I.

although the mean duration of lost response was longer after muscimol than saline injection in the MR.

An enhanced behavioral hyperactivity after pentobarbital was observed in rats after MR muscimol or saline infusion compared to baseline values. As seen in Figure $5 \mathrm{~d}$, both muscimol- and saline-infused rats showed a significant $\left(\mathrm{F}_{(5,90)}=13.28\right.$ and 23.60 respectively, $p<0.001$, one-way ANOVA) increase in locomotor activity at $1-4 \mathrm{~min}$ after injection of pentobarbital. Similar to halothane, pentobarbital induced higher locomotor activity in muscimolinfused as compared to saline-infused rats, as confirmed by a significant group $\times$ time interaction $\left(\mathrm{F}_{(15,75)}=4.00\right.$, $p<0.0001$, two-way ANOVA).

There were no significant differences in the duration of lost foot/tail pinch responses or righting reflex between MR saline- and muscimol-injected rats tested after i.p. injection of pentobarbital ( $p=0.72$ and 0.11 , respectively; Figure $5 b)$.
Hippocampal EEGs after Infusion of Muscimol and Saline in Various Structures and Anesthetics

Six rats were used to examine the effect of muscimol infusion alone into the SUM on hippocampal EEGs. Muscimol infusion in SUM significantly suppressed hippocampal theta compared to baseline walking $(z=2.20$; $p<0.05$, Wilcoxon test), while saline infusion in SUM was without significant effect $(z=1.57, p=0.12)$. Other EEG frequency bands, delta $(1-4 \mathrm{~Hz})$ and gamma power, were not significantly affected by muscimol or saline infusion in the SUM (data not shown).

EEGs after halothane and pentobarbital were studied in separate experiments (Methods), focusing on injections in the NAC, VP and MR. At 1-4 min after administration of halothane, rats with saline infused in the NAC or other structures showed increased behavioral excitation (hyperlocomotion), accompanied by a slow $(\sim 6 \mathrm{~Hz})$ hippocampal 


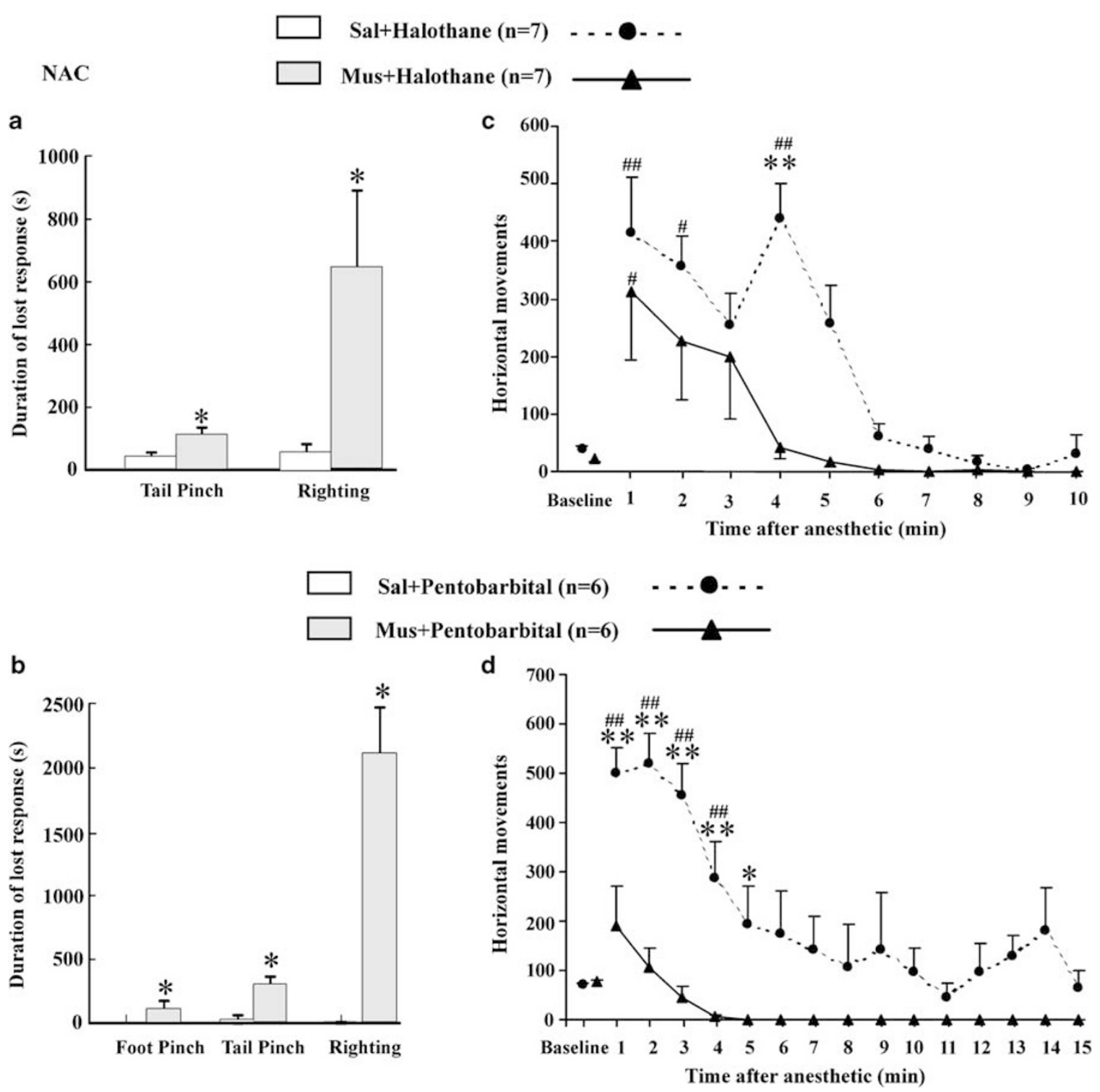

Figure 3 Inactivation of nucleus accumbens (NAC) by muscimol infusion prolonged halothane's effect on (a) the duration of lost pain and righting responses (foot pinch was not tested) and (c) reduced halothane-induced horizontal movements indicated by infrared beam interruptions. (b and d) Effects after pentobarbital. Layout and symbols as in Figure I.

theta rhythm ( $\theta$ in Figure 6a). At the same time, hippocampal gamma waves of $25-50 \mathrm{~Hz}(\gamma$ in Figure 6a; $\Delta$ Early phase in Table 1a) were increased from the baseline. Hippocampal theta power after halothane, whether during immobility (Figure 6b) or walking (Figure 6a), was larger than that during walking before halothane. Theta and gamma power decreased subsequently at $>7 \mathrm{~min}$ after halothane, but remained above baseline values even when the rat was unable to walk (Figure $6 \mathrm{~b} ; \Delta$ Late phase in Table 1a). If the administration of halothane was preceded by muscimol infusion in the NAC, increase of hippocampal theta or gamma waves was not found after halothane at any time (Figure $6 \mathrm{c}$ and $\mathrm{d}$ ). Muscimol infusion in the NAC alone suppressed hippocampal EEG at frequencies $>6 \mathrm{~Hz}$ (Figure $6 \mathrm{c}$ and Table $3 \mathrm{a}$ ) and halothane administration further suppressed high-frequency gamma EEG (Figure 6c, $\mathrm{d}$ and Table 1a). As reported above, the rat was not behaviorally excited by halothane after muscimol infusion in the NAC. Both EEG and behavior indicated a deep state of anesthesia in muscimol-infused rats at 3-4 min after halothane (early phase). Hippocampal delta $(1-4 \mathrm{~Hz})$ was not significantly affected by halothane, either after saline or muscimol infusion in the NAC (Table 1).

Pentobarbital (20 mg/kg i.p.) induced similar EEG effects as halothane in saline-infused rats, with a few exceptions. During the behavioral excitation phase, pentobarbital (20 mg/kg i.p.) increased hippocampal gamma power of $25-50 \mathrm{~Hz}$ except hippocampal theta was less pronounced after pentobarbital (Figure $6 \mathrm{e}, \mathrm{f}$ ) than after halothane. In rats with muscimol infused in the NAC, no increase in hippocampal gamma and theta power (Figure $6 \mathrm{~g}, \mathrm{~h}$ ) or locomotion (Figure 3d) was found after pentobarbital. Instead, muscimol infusion in the NAC significantly suppressed the hippocampal theta power. Muscimol alone 

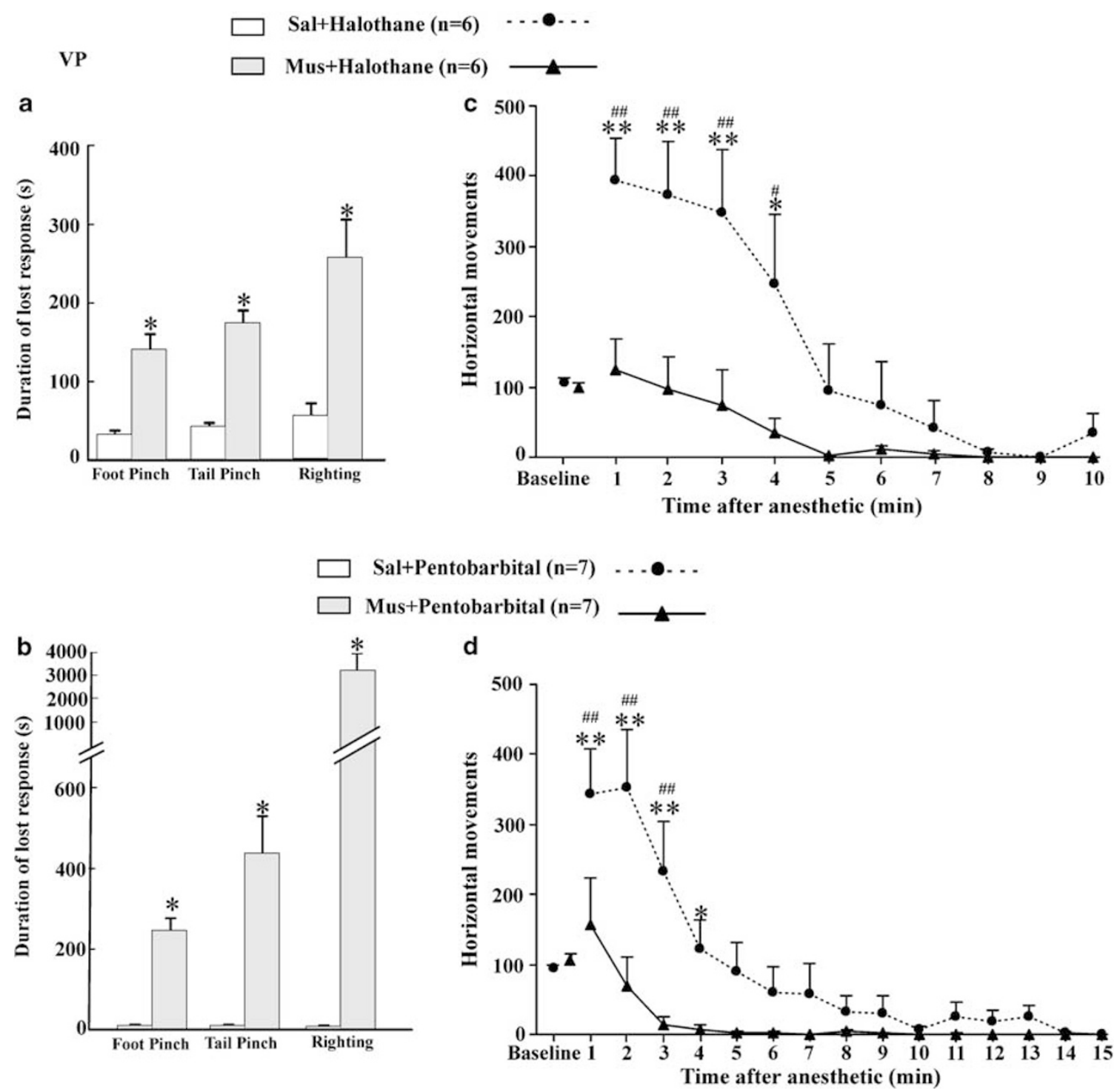

Figure 4 Inactivation of ventral pallidum (VP) by muscimol infusion prolonged the duration of lost pain and righting responses (a and b) and reduced horizontal movements ( $c$ and d) induced by halothane $(a, c)$ or pentobarbital (b, d). Layout and symbols as in Figure I.

in NAC also suppressed hippocampal gamma EEG, but this effect was not statistically significant (Table 3a), and a greater suppression of hippocampal gamma occurred after pentobarbital (Figure 6g, h and Table 2a), accompanied by increased hippocampal delta (Figure $6 \mathrm{~h}$ and Table 2a).

Muscimol and saline infusion in the VP had similar effects on hippocampal EEG as infusions in the NAC. Briefly, saline-infused rats showed an early increase in gamma waves after halothane and after pentobarbital, and the gamma power increase was greatly attenuated in muscimol-infused rats (Tables $1 \mathrm{~b}$ and 2b). Muscimol infusion in the VTA $(N=2)$ gave similar effects on hippocampal EEGs as muscimol infusion in VP or NAC (data not shown). In contrast, muscimol infusion alone in the MR showed hyperactivity accompanied by a hippocampal theta rhythm (Figure 7c) that was not significantly different in power or frequency during baseline walking or that after saline infusion in the MR (Figure 7a). Baseline theta frequency was $7.32 \pm 0.55 \mathrm{~Hz} \quad(N=7)$. Muscimol infusion in MR did not significantly alter the gamma power increase after halothane (Table 1c) or pentobarbital (Table 2c; Figures 7c, d), and it did not change the hippocampal theta response to halothane. However, MRmuscimol infusion did significantly enhance hippocampal theta during immobility at $8-13 \mathrm{~min}$ after pentobarbital (Figure $7 \mathrm{~d} ; \mathrm{F}_{(1,6)}=54.78, p<0.001$, two-way ANOVA). The latter immobility-related theta frequency was $7.63 \pm 0.21 \mathrm{~Hz}$ $(N=7)$ at $10 \mathrm{~min}$ after pentobarbital, not significantly different from the theta frequency during baseline walking.

\section{Neocortical EEG after Infusions and Anesthetics}

Similar to hippocampal gamma waves, neocortical gamma waves also increased significantly during the early (behavioral excitation) phase of anesthesia induced by either halothane (Figure 8a; Table 1) or pentobarbital (Figure 8e, Table 2) in saline-infused rats. Local muscimol infusions into the NAC and VP, but not MR, attenuated or reversed 
the increase in gamma activity during the early phase of anesthesia (Figure 8c, g) and increased the depression of gamma waves during the late phase (Figure $8 \mathrm{~b}, \mathrm{f}$ ). Muscimol infusion alone into MR, NAC or VP did not significantly affect neocortical gamma waves compared to saline injections (Table 3).

Neocortical delta $(1-4 \mathrm{~Hz})$ power increased during the late phase of halothane (Figure $8 \mathrm{~b}$ ) or pentobarbital
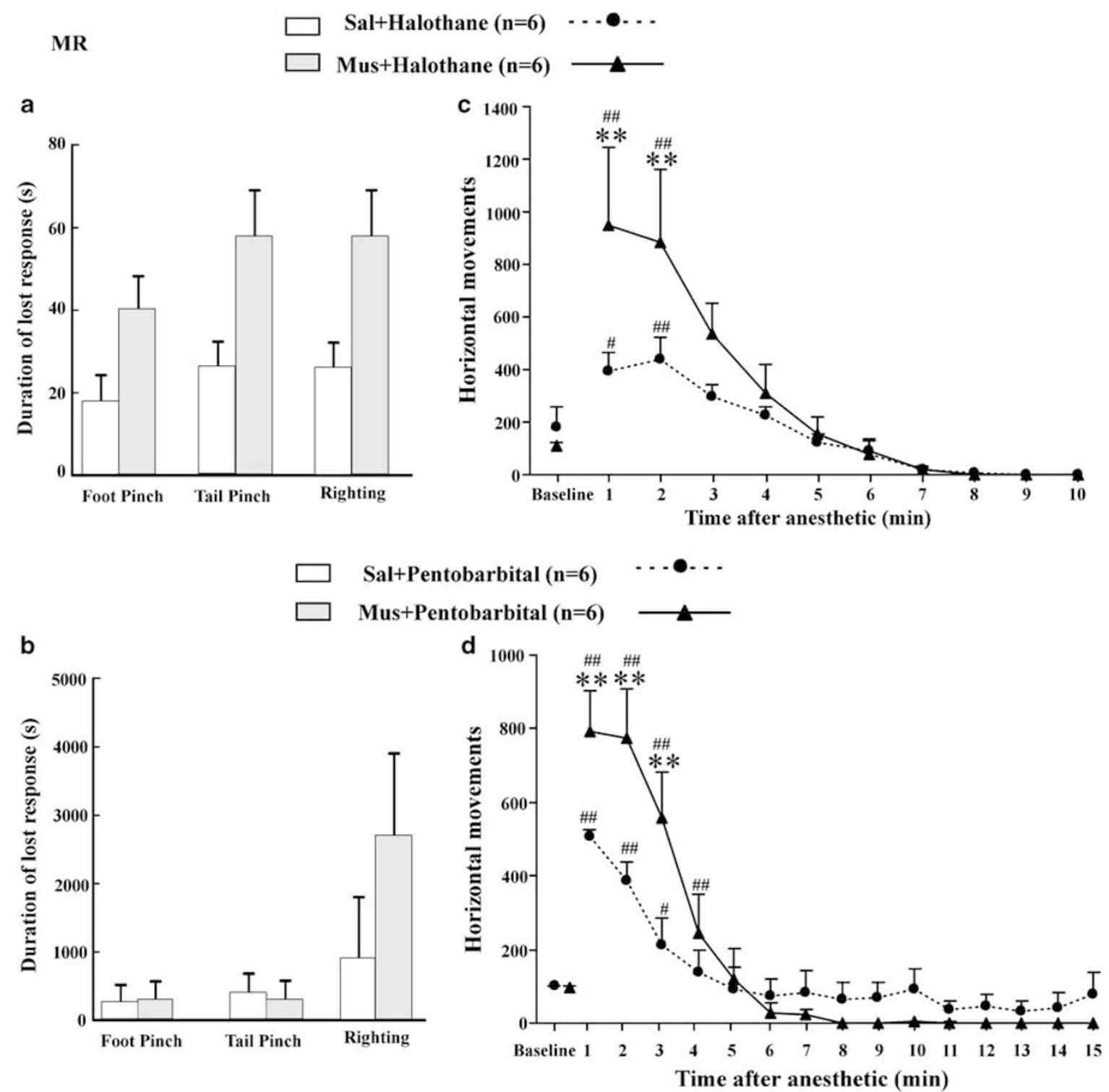

Figure 5 Inactivation of median raphe (MR) by muscimol infusion did not significantly prolong the duration of lost pain and righting responses (a and b). However, muscimol in the MR increased the horizontal movements ( $c$ and $d$ ) induced by halothane or pentobarbital. Layout and symbols as in Figure I.

Figure 6 Representative hippocampal EEG power spectra in rats after muscimol or saline injection in the nucleus accumbens (NAC), followed by $2 \%$ halothane (left column, a-d, rat 349) or $20 \mathrm{mg} / \mathrm{kg}$ i.p. pentobarbital (right column, e-h, rat 4I0). EEG was recorded at CAI stratum radiatum of the dorsal hippocampus. (a) Power spectrum during behavioral excitation at 4 min after administration of halothane (dark trace) in a saline (Sal)-injected rat shows large theta $(\theta)$ and $25-50 \mathrm{~Hz}$ gamma waves $(\gamma)$, as compared to baseline walking before injection (gray trace) or walking after saline (Sal) injection (thin trace). (b) At $10 \mathrm{~min}$ after halothane (dark trace), the rat became immobile (imm) but showed a $5-6 \mathrm{~Hz} \theta$ and a low broad-peaked gamma waves as compared to baseline spectrum during immobility before (gray trace) and after saline injection (thin trace). (c) In another experiment, muscimol (Mus) injection in the NAC alone suppressed theta and gamma activities during induced walking (thin trace) as compared to the baseline walking spectrum (gray trace). Halothane administration after muscimol injection induced no behavioral excitation or gamma peak in the EEG spectrum (dark trace; at 4 min after) and decreased further the $>50 \mathrm{~Hz}$ gamma EEG power. (d) At 10 min after halothane, the rat showed a large delta $(\mathrm{I}-4 \mathrm{~Hz})$ power, no theta peak, and decreased gamma power (dark trace) as compared to baseline immobility (gray trace). Rat was not responsive to pain or righting at this time. Muscimol injection alone (thin trace) did not affect delta and other EEG power. (e) Gamma waves increased at 4 min after pentobarbital in a saline-injected rat (dark trace), during behavioral excitation, compared with baseline walking (gray trace). (f) At I 5 min after pentobarbital, EEG spectrum (dark trace) was not significantly altered from the immobile baseline spectrum (gray trace). (g) No increase of gamma waves was found at 4 min after pentobarbital injection (dark traces) in the same rat as $E$ after muscimol injection in the NAC, compared to baseline walking (gray trace). (h) At 10 min after muscimol injection and pentobarbtial, spectrum shows increased delta power and decreased gamma power (black trace) as compared with baseline immobile (gray trace). 
(Figure 8f), in rats with saline injected in the NAC, VP, and MR (Tables 1 and 2). Muscimol infusion alone to the NAC and VP also increased neocortical delta power (Table 3), but the delta power after halothane (Figure 8d; Table 1) or after pentobarbital (Figure $8 \mathrm{~h}$; Table 2) in muscimol-infused rats was not significantly larger than the corresponding measure in saline-infused rats. Similar results were found with muscimol/saline infusions in the VP (Tables $1 \mathrm{~b}$ and $2 \mathrm{~b}$ ) as compared to infusions in NAC. In contrast, muscimol
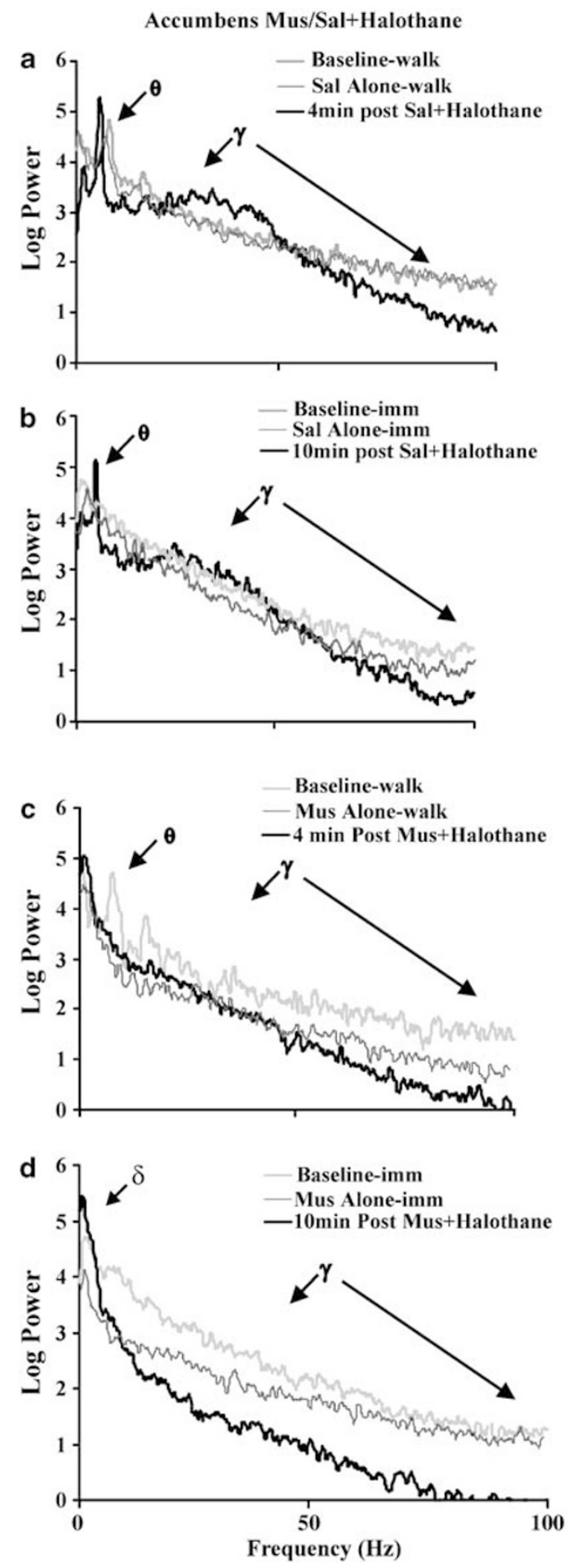

infusion into the MR did not change the neocortical delta/ gamma response or the behavioral responses to halothane or pentobarbital (Tables 1c and 2c).

\section{DISCUSSION}

Infusion of muscimol into the NAC, VP, SUM, or VTA potentiated the anesthetic effects of halothane or pentobarbital, as shown by the prolonged duration of loss of
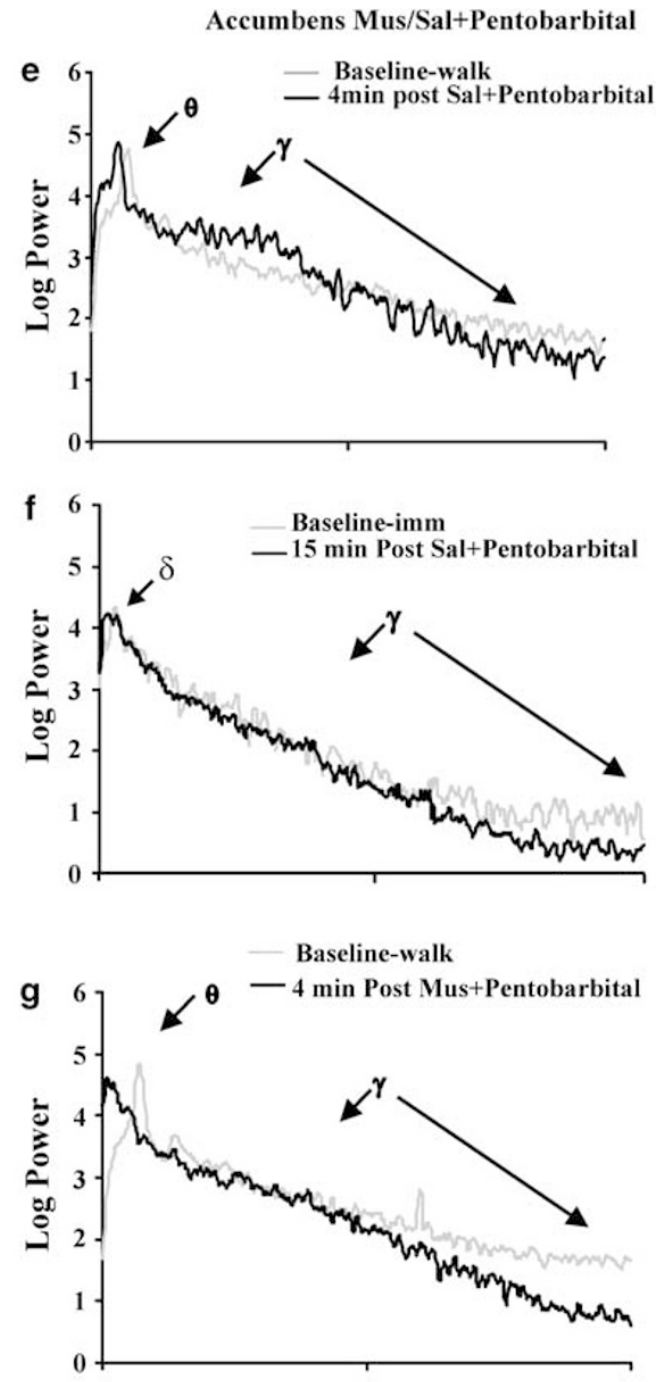

h

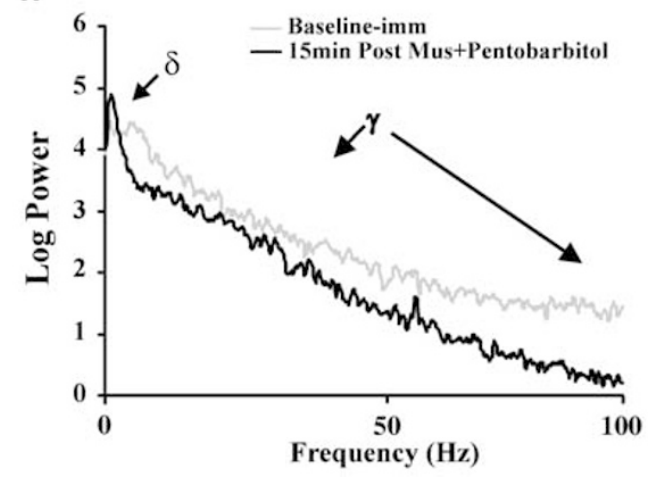


Table I Halothane (2\%) Induced Changes in Power of Hippocampal and Neocortical EEGs of Various Frequency Bands, Following Saline or Muscimol Injection into Nucleus Accumbens, Ventral Pallidum or Median Raphe

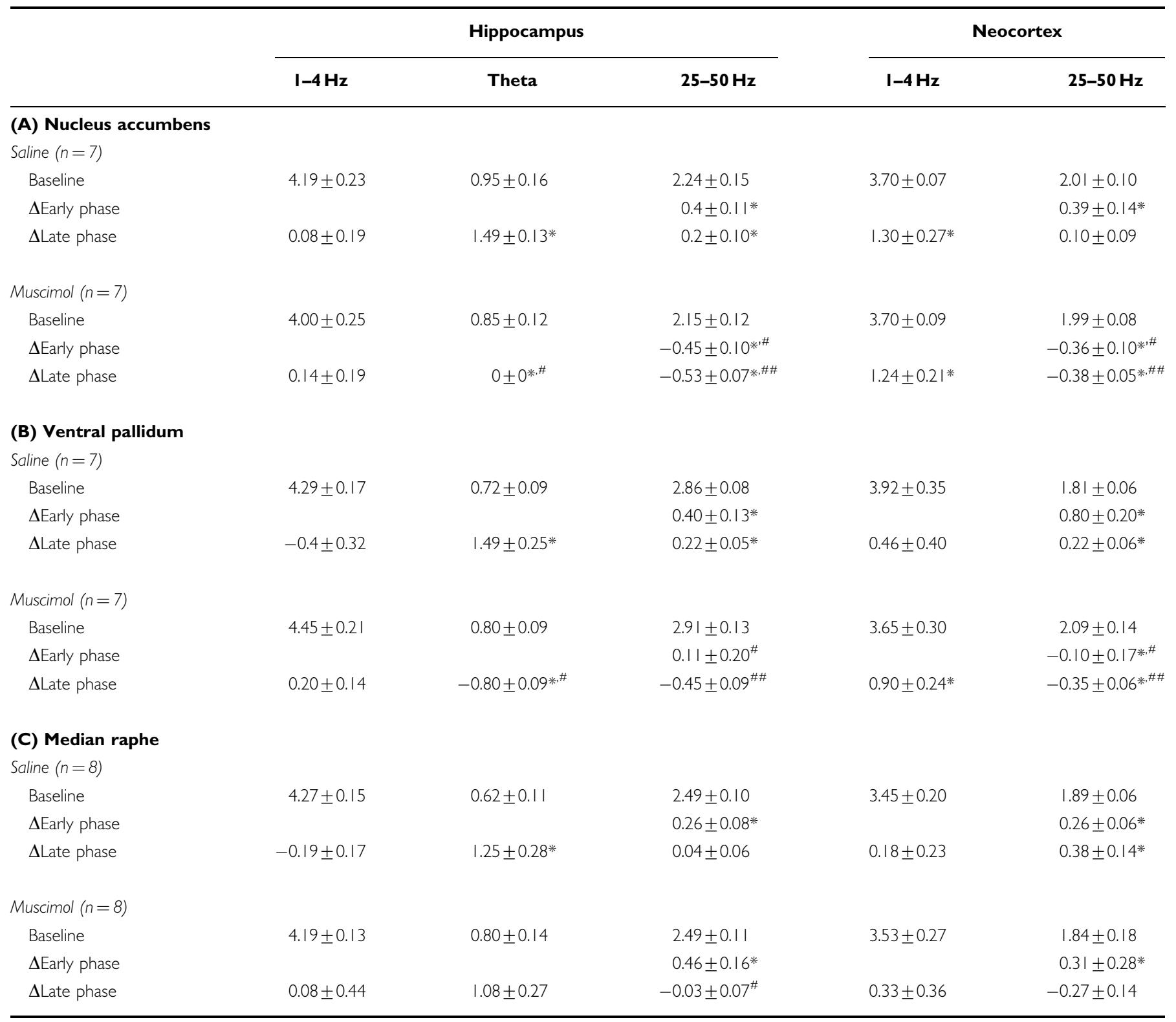

The first row 'Baseline' indicates power in logarithmic units during baseline, with $\mathrm{I}-4 \mathrm{~Hz}$ recorded during immobility; theta and $25-50 \mathrm{~Hz}$ power were recorded during baseline walking, and 'Theta' indicates the height of the theta power peak (in log units), measured from the rise to the peak. $\Delta$ Early phase and $\Delta$ Late phase indicate the change in power from baseline during early ( I-4 min) and late ( $7-10 \mathrm{~min})$ phase, respectively, after halothane. ${ }^{*} p<0.05$, significantly different from baseline, ${ }^{\#} p<0.05$; $\#$ \# $<0.01$, significantly different between saline- and muscimol-injected rats using paired Wilcoxon test. Entries are mean \pm SEM (number of rats).

response to pain and to righting. The behavioral excitation and the increase in hippocampal/neocortical gamma waves induced by halothane or pentobarbital were suppressed when the NAC, VP, SUM, or VTA was inactivated. Inactivation of NAC and VP alone was found to significantly increase neocortical delta waves, suggesting that cortical activation is reduced.

Infusion of muscimol allows reversible inactivation of a brain structure and avoids the problems associated with permanent lesions, such as brain plasticity. The same animal can also be used for control experiments. However, the infused muscimol/vehicle is expected to diffuse 1-
$1.7 \mathrm{~mm}$ radius away from the site of infusion, based on autoradiography (Martin, 1991) and on physiological or behavioral recordings ( $\mathrm{Ma}$ et al, 2002). For targets in this study, diffusion was likely minimal outside of the NAC, and minor for MR and VP infusions (discussed below). However, SUM and VTA targets were located near each other, and based on the histological sections of the cannula sites, it is likely that infusion of SUM spread to VTA, and vice versa. Muscimol infused at SUM/VTA targets may also diffuse to the tuberomammillary nucleus (TBN). Muscimol infused into the TBN induced a loss of righting reflex (Nelson et al, 2002). 
Table 2 Pentobarbitial (20 mg/kg i.p.) Induced Hippocampal/Neocortical EEG Power (mean \pm SEM) before and after Muscimol/Saline Injections into the Nucleus Accumbens, Ventral Pallidum and the Median Raphe

\begin{tabular}{|c|c|c|c|c|}
\hline & \multicolumn{2}{|c|}{ Hippocampus } & \multicolumn{2}{|c|}{ Neocortex } \\
\hline & $\mathrm{I}-4 \mathrm{~Hz}$ & $25-50 \mathrm{~Hz}$ & $\mathrm{I}-4 \mathrm{~Hz}$ & $25-50 \mathrm{~Hz}$ \\
\hline \multicolumn{5}{|c|}{ (A) Nucleus accumbens } \\
\hline \multicolumn{5}{|l|}{ Saline $(n=7)$} \\
\hline Baseline & $4.03 \pm 0.12$ & $2.41 \pm 0.20$ & $3.48 \pm 0.21$ & $1.95 \pm 0.22$ \\
\hline \multicolumn{5}{|l|}{ Muscimol $(n=7)$} \\
\hline Baseline & $3.97 \pm 0.13$ & $2.34 \pm 0.16$ & $3.59 \pm 0.13$ & $1.95 \pm 0.19$ \\
\hline$\Delta$ Early phase & & $-0.28 \pm 0.14^{* \prime \prime}$ & & $-0.26 \pm 0.28^{\#}$ \\
\hline$\Delta$ Late phase & $0.60 \pm 0.13^{*}$ & $-0.45 \pm 0.05^{*}, \# \#$ & $0.92 \pm 0.16 *$ & $-0.30 \pm 0.10^{\# \#}$ \\
\hline \multicolumn{5}{|c|}{ (B) Ventral pallidum } \\
\hline \multicolumn{5}{|l|}{ Saline $(n=7)$} \\
\hline Baseline & $4.35 \pm 0.25$ & $2.81 \pm 0.13$ & $3.64 \pm 0.23$ & $1.81 \pm 0.06$ \\
\hline$\Delta$ Early phase & & $0.5 \pm 0.06^{*}$ & & $0.80 \pm 0.20 *$ \\
\hline$\Delta$ Late phase & $0.26 \pm 0.12$ & $0.14 \pm 0.05$ & $0.48 \pm 0.22 *$ & $0.22 \pm 0.06 *$ \\
\hline \multicolumn{5}{|l|}{ Muscimol $(n=7)$} \\
\hline Baseline & $4.52 \pm 0.19$ & $3.02 \pm 0.07$ & $3.63 \pm 0.33$ & $2.09 \pm 0.14$ \\
\hline$\Delta$ Early phase & & $-0.17 \pm 0.23^{\#}$ & & $-0.10 \pm 0.18^{\#}$ \\
\hline$\Delta$ Late phase & $0.30 \pm 0.15$ & $-0.4 I \pm 0.05^{*} \# \#$ & $1.23 \pm 0.20 *$ & $-0.35 \pm 0.06^{\# \#}$ \\
\hline \multicolumn{5}{|c|}{ (C) Median raphe } \\
\hline$\Delta$ Early phase & & $0.21 \pm 0.08$ & & $0.57 \pm 0.18^{*}$ \\
\hline$\Delta$ Late phase & $0.001 \pm 0.33$ & $-0.06 \pm 0.05^{\#}$ & $0.13 \pm 0.19$ & $0.39 \pm 0.07$ \\
\hline
\end{tabular}

Layout as in Table I. ${ }^{*} p<0.05$ (number of rats) compared to baseline, ${ }^{\#} p<0.05 ;{ }^{\#} p<0.01$ compared to saline-injected rats using paired Wilcoxon test.

\section{Limbic Circuit and General Anesthesia}

The findings here extended earlier results that muscimol inactivation of the medial septum or the hippocampus potentiated the behavioral and EEG effects induced by a general anesthetic (Ma et al, 2002). Muscimol inactivation of the NAC, VP, SUM, and VTA also potentiated the effects of a general anesthetic, similar to inactivation of the medial septum. In contrast, muscimol inactivation of the MR did not potentiate the anesthesia induced by halothane or pentobarbital. Thus, many but not all parts of the limbic system participate in general anesthesia. Based on the neuroanatomical literature (Groenewegen et al, 1987; Mogenson et al, 1993), it may be suggested that a hippocampus-NAC-VP circuit participates in general anesthesia. Since movement suppression is an essential component of general anesthesia, the present results may be explained by inactivation of a movement initiation circuit in the limbic system. The hippocampus has long been suggested to participate in voluntary movements (Vanderwolf, 1969) and the NAC-VP pathway is known to mediate locomotor effects of the hippocampus and other limbic areas (Ma et al, 1996; Mogenson et al, 1993).

Inactivation of some structures in the present study affects the EEG of the cerebral cortex including the hippocampus. NAC, VP, or SUM inactivation decreased hippocampal and neocortical EEG activation, increased slow delta activity, and decreased gamma (fast) waves. Hippocampal theta and fast waves (Bland and Oddie, 2001; Leung, 1998; Vanderwolf, 1988) and neocortical desynchro- 
Median Raphe Mus/Sal+Pentobarbital
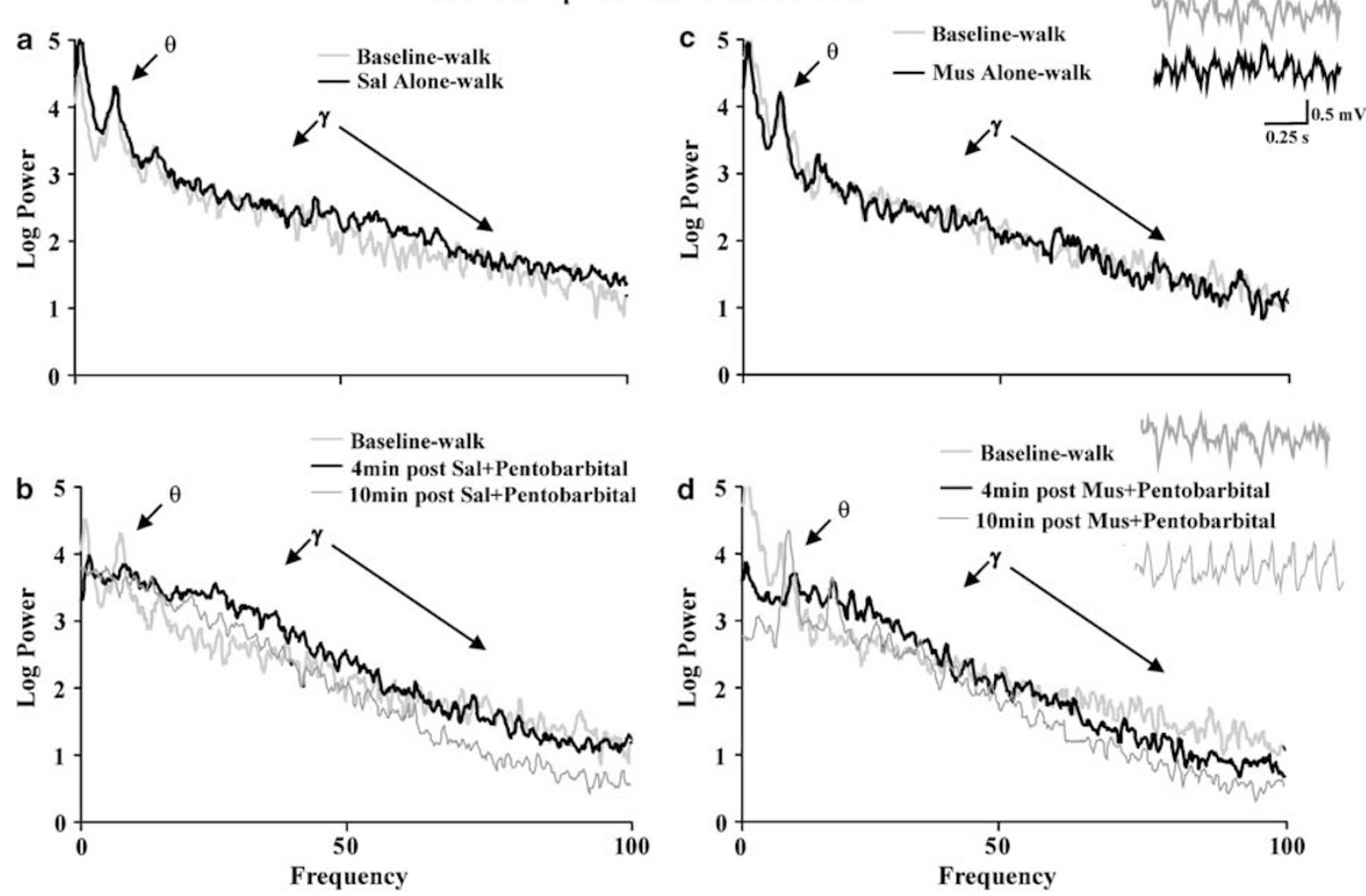

Figure 7 Representative hippocampal EEG power spectra after muscimol or saline injection in the median raphe, followed by i.p. pentobarbital (rat 466) EEG was recorded at CAI stratum radiatum of the dorsal hippocampus. (a) Saline injection alone (black traces) did not affect hippocampal EEG compared to baseline (thick grey traces) during walking. (b) Hippocampal theta rhythm was suppressed and gamma waves increased at 4 min after pentobarbital (black trace) in saline-injected rats compared with baseline walking (grey trace). At 10 min after pentobarbital, theta rhythm (thin trace) was still absent and gamma waves were decreased. (c) Muscimol injection alone (black traces) did not affect hippocampal EEG compared to baseline (thick grey traces) during walking. Inset in (c) shows raw EEG traces. (d) In the muscimol-injected rat, theta and gamma waves were not pronounced during immobility at 4 min after pentobarbital. However, a robust increase in theta rhythm was observed at 10 min after pentobarbital injection when the rat was immobile (thin trace), with a peak frequency of $7.5 \mathrm{~Hz}$. Inset in (d) shows raw EEG traces.

nization and gamma waves (Berntson et al, 2002; Cape and Jones, 2000; Steriade and Amzica, 1996) are indicators of cortical activation. We suggest that suppression of neocortical and hippocampal activation contributes to the effects of a general anesthetic. Behavioral excitation and cortical activation that normally accompanied early anesthetic action were abolished by inactivation of the NAC, VP, SUM, or VTA. Hippocampal theta rhythm that accompanied surgical anesthesia of some anesthetics (eg, halothane and urethane; see also Bland et al, 2003; Stumpf, 1965; Vanderwolf, 1988) was also abolished by inactivation of NAC, VP, or SUM (this study), as well as by inactivation of the medial septum and hippocampus (Ma et al, 2002). There has been increasing recognition that normal arousal processes participate in general anesthesia (Tung and Mendelson, 2004), and in addition to the tuberomammillary nucleus (Nelson et al, 2002), the mesopontine tegmentum (Devor and Zalkind, 2001) and the septohippocampal system (Ma et al, 2002), this study shows that inactivation of structures that mediate normal arousal enhances the effect of a general anesthetic.

Inactivation of the MR did not significantly prolong the anesthetic-induced loss of righting or pain responses. In fact, muscimol infused into the MR induced hyperlocomo- tion that may be mediated by serotonergic (Sainati and Lorens, 1982) or nonserotonergic neurons (Shim et al, 1997). Muscimol as compared to saline infused into the MR increased the locomotion induced by halothane or pentobarbital, without affecting the pain and righting response tested 25-30 min after muscimol infusion. This suggests that locomotor activity increase (behavioral excitation) induced by a general anesthetic can be dissociated from the subsequent loss of righting and pain responses.

Electrical lesion of dorsal raphe was shown to decrease serotonin in the neocortex and the anesthetic requirement for halothane (Roizen et al, 1978). Systemic blockade of serotonin receptors enhanced the loss of righting induced by several types of anesthetics including pentobarbital (Dringenberg, 2000). In contrast, we did not find a statistically significant effect in potentiating anesthesia when MR was inactivated by muscimol. One possible explanation is that the anesthetic dose used in this study was low. At $22 \mathrm{mg} / \mathrm{kg}$ i.p. pentobarbital, serotonin receptor antagonists were not found to enhance pentobarbital's anesthetic effects (Dringenberg, 2000). In addition, inactivation of $M R$ in this study is different from systemic blockade of serotonin receptors, since the MR projects predominantly to the limbic system. 
Accumbens Mus/Sal+Halothane
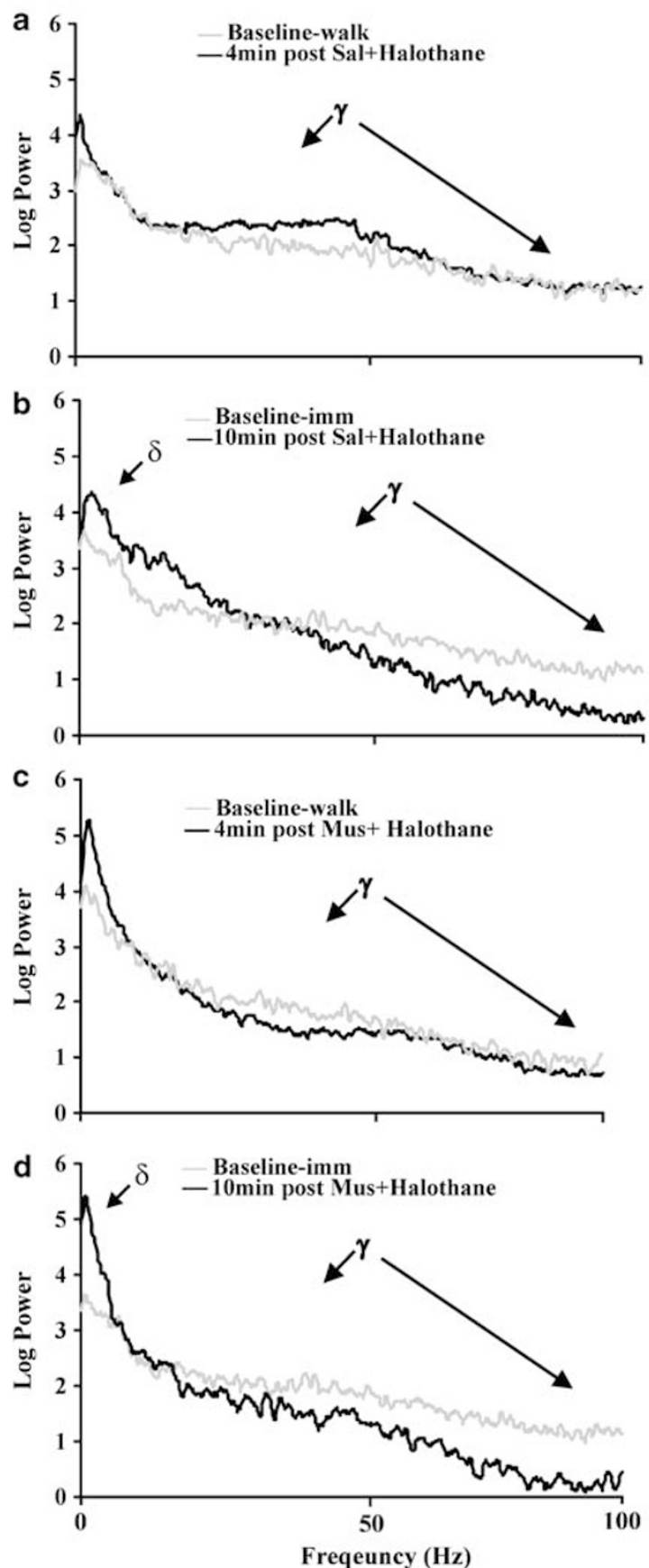

Accumbens Mus/Sal+Pentobarbital
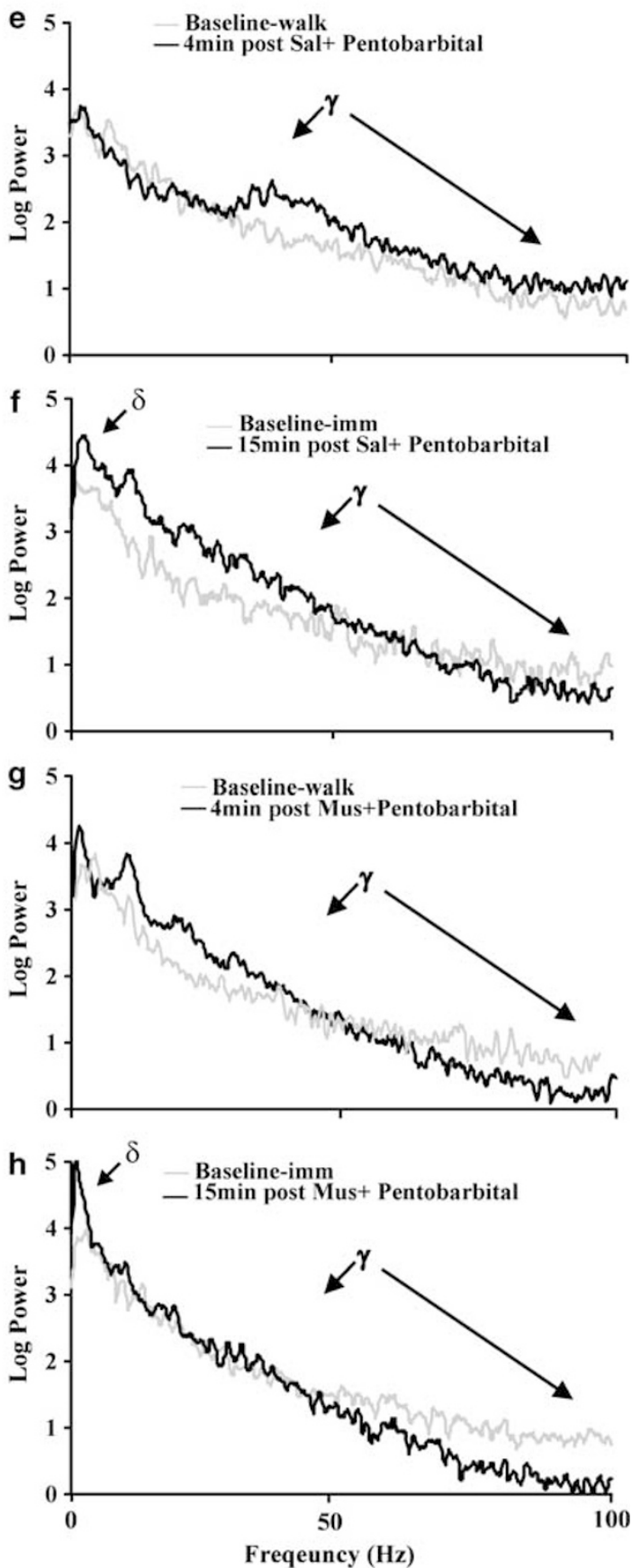

Figure 8 Representative neocortical EEG spectra following nucleus accumbens (NAC) muscimol or saline injection plus 2\% halothane (left column; rat 344) or pentobarbital $(20 \mathrm{mg} / \mathrm{kg}$ i.p.; rat 5I I). EEG was recorded in the deep layers of the frontal cortex. (a) In a saline (Sal)-injected rat, gamma waves showed an increase at $4 \mathrm{~min}$ after introduction of halothane during behavioral excitation (black trace) as compared baseline walking (gray trace). (b) At 10 min after halothane, gamma waves $(\gamma)$ were suppressed and slow waves of $\mathrm{I}-4 \mathrm{~Hz}(\delta)$ were increased (black trace) compared with immobility (imm) during baseline (grey trace). Unlike hippocampal EEGs, theta rhythm was not observed. (c) In a different experiment, the same rat given muscimol (Mus) injection in NAC showed no behavioral excitation and no increase in gamma waves at 4 min after halothane (black trace) compared with baseline walking (grey trace). (d) At 10 min after halothane, muscimol-injected rat showed further decrease in gamma waves and an increase in I $-4 \mathrm{~Hz}$ slow waves $(\delta$ ). (e) Gamma waves showed an increase during behavioral excitation at 4 min after pentobarbital in a saline-injected rat (black trace) compared with baseline walking (grey trace). (f) At 15 min after pentobarbital, EEG power generally increased in $1-50 \mathrm{~Hz}$ including $\mathrm{I}-4 \mathrm{~Hz}$ (black trace) compared with baseline immobile (gray trace). (g) The same rat after muscimol-NAC and then pentobarbital injection showed no gamma peak 4 min after pentobarbital (black trace) compared to baseline walking (gray trace). (h) At 15 min after pentobarbital, high-amplitude $1-4 \mathrm{~Hz}$ slow waves (black trace) and decreased gamma waves were observed compared with baseline immobile (gray trace).

Hyperlocomotion during recovery from isoflurane was suggested to be mediated by dopamine in the NAC and dorsal striatum (Irifune et al, 1997). A similar increase in dopamine function in the NAC may underlie the increase in locomotion during induction of halothane or pentobarbital anesthesia. Previous studies have shown that locomotor 
Table 3 Effects of Muscimol/Saline Injection Alone on Hippocampal/Neocortical EEGs (mean \pm SEM)

\begin{tabular}{|c|c|c|c|c|c|}
\hline & \multicolumn{3}{|c|}{ Hippocampus } & \multicolumn{2}{|c|}{ Neocortex } \\
\hline & $\mathrm{I}-4 \mathrm{~Hz}$ & Theta & $25-50 \mathrm{~Hz}$ & $\mathrm{I}-4 \mathrm{~Hz}$ & $25-50 \mathrm{~Hz}$ \\
\hline \multicolumn{6}{|l|}{ Saline $(n=7)$} \\
\hline Baseline & $4.26 \pm 0.22$ & $0.88 \pm 0.13$ & $2.38 \pm 0.17$ & $3.65 \pm 0.05$ & $2.01 \pm 0.09$ \\
\hline \multicolumn{6}{|l|}{ Muscimol $(n=7)$} \\
\hline Baseline & $4.06 \pm 0.24$ & $0.80 \pm 0.11$ & $2.31 \pm 0.19$ & $3.69 \pm 0.09$ & $2.03 \pm 0.08$ \\
\hline$\Delta$ Post-inject & $-0.02 \pm 0.18$ & $-0.45 \pm 0.14^{\#}$ & $-0.19 \pm 0.08$ & $0.67 \pm 0.19^{*, \#}$ & $-0.18 \pm 0.07$ \\
\hline \multicolumn{6}{|c|}{ (B) Ventral pallidum } \\
\hline \multicolumn{6}{|l|}{ Muscimol $(n=7)$} \\
\hline Baseline & $4.86 \pm 0.14$ & $0.81 \pm 0.08$ & $2.95 \pm 0.11$ & $3.47 \pm 0.23$ & $2.12 \pm 0.19$ \\
\hline$\Delta$ Post-inject & $0.37 \pm 0.15$ & $-0.15 \pm 0.17$ & $-0.07 \pm 0.06$ & $0.67 \pm 0.24 *$ & $-0.32 \pm 0.12$ \\
\hline \multicolumn{6}{|c|}{ (C) Median raphe } \\
\hline \multicolumn{6}{|l|}{ Saline $(n=8)$} \\
\hline Baseline & $4.11 \pm 0.21$ & $0.84 \pm 0.08$ & $2.57 \pm 0.11$ & $3.65 \pm 0.31$ & $1.81 \pm 0.16$ \\
\hline$\Delta$ Post-inject & $0.12 \pm 0.16$ & $0.13 \pm 0.1$ & $0.04 \pm 0.03$ & $0.06 \pm 0.03$ & $-0.21 \pm 0.11$ \\
\hline
\end{tabular}

Injections were made into nucleus accumbens, ventral pallidum or median raphe, and layout and explanation as in Table I. $\Delta$ Post-inject is the difference in power after injection of saline/muscimol and the baseline. ${ }^{*} p<0.05$ (number of rats) compared to baseline, ${ }^{*} p<0.05$ compared to saline-injected rats using paired Wilcoxon test.

hyperactivity induced by hippocampal excitation was mediated by NAC (Ma et al, 1996; Mogenson et al, 1993).

Analgesic effects mediated by NAC and VTA had been reported (Altier and Stewart, 1998; Gear et al, 1999; Ma and Han, 1991). Based on these studies, it is not obvious if inactivation of NAC or VTA will potentiate the analgesic effect of a general anesthetic, as has been shown here.

Muscimol infusion into the SUM, VTA, VP, and NAC suppressed voluntary movements and the movements induced by a general anesthetic, suggesting that these structures regulate motor behavior as well. Behavioral excitation induced by subanesthetic doses of halothane or pentobarbital is probably equivalent to the delirium state that usually occurs in humans during induction (Cohen, 1975; Guedel, 1951) or during recovery from an anesthetic (Wells and Rash, 1999). While inactivation of SUM, VTA, VP, NAC (this study), and the septohippocampal system (Ma et al, 2002) depressed initial behavioral excitation and potentiated subsequent general anesthesia, the two stages of general anesthesia may have different mechanisms. One example is that rats following infusion of muscimol in the MR showed increased behavioral excitation but not anesthesia after halothane or pentobarbital.

\section{NAC, VP, SUM and VTA Participate in the Generation of Cortical/Hippocampal EEG}

We showed that inactivation of SUM suppressed the hippocampal theta rhythm of behaving rats, as has been shown for anesthetized rats (Kirk et al, 1996; Kirk and McNaughton, 1993). Electrophysiological studies suggested that SUM provides the frequency that drives a hippocampal theta rhythm (Kirk et al, 1996; Kirk and McNaughton, 1993). SUM receives afferents from the pontine reticular formation and pontis oralis (Vertes and Martin, 1988) and projects glutamatergic/aspartaergic fibers to the medial septum (Borhegyi et al, 1998; Kiss et al, 2000). Thus, the suppression of theta and gamma in the hippocampus after SUM inactivation is consistent with the fact that SUM is a part of an arousal/sleep-wake system. Inactivation of VTA and TBN after muscimol infusion in the SUM may also contribute to hippocampal EEG suppression.

Inactivation of the VP and NAC had an effect in enhancing delta in the neocortex. The inactivation induced a state of immobility during which it was difficult to induce the rat to move voluntarily. Thus, the suppression of hippocampal theta after inactivation of VP and NAC was 
interpreted as a secondary effect of movement suppression, but the suppression of hippocampal theta induced by halothane may be interpreted as an increase in the level of general anesthesia. The effect on inactivation of VP on neocortical EEG may also be explained by inactivation of basal forebrain neurons in and around the VP that project to the neocortex (Saper, 1984; Semba, 2000). Basal forebrain neurons are known to mediate desynchronization of slow (delta) waves (Stewart et al, 1984; Vanderwolf, 1988). The GABAergic neurons in the VTA were sensitive to changes in sleep states and general anesthesia (Lee et al, 2001), and VTA lesion decreased hippocampal theta during explorative sniffing (Jurkowlaniec et al, 2003). The profound effect of muscimol in the NAC on EEG and behavior, with or without halothane, was not expected. To our knowledge, there is no direct neural pathway from the NAC to the hippocampus. Among other structures, NAC projects to the pedunculopontine tegmental area (Berendse et al, 1992; Yang and Mogenson, 1987; Reese et al, 1995) that may influence hippocampal EEG through the hypothalamus and medial septum (Bland and Oddie, 2001; Kirk and McNaughton, 1993).

MR infusion of muscimol $(0.5-1 \mu \mathrm{g})$ has been shown to enhance hippocampal theta rhythm in urethane-anesthetized rat (Kinney et al, 1995). We are not aware of a systematic study of hippocampal EEG after muscimol inactivation of the $\mathrm{MR}$ in the behaving rat. Electrolytic lesion of the MR induced persistent hippocampal theta rhythm during immobility (Maru et al, 1979; Yamamoto et al, 1979). We did not see a significant increase of hippocampal theta during walking after muscimol $(0.25 \mu \mathrm{g})$ infuion in the MR, as compared to baseline walking. Further enhancement of theta power after MR-muscimol may not be expected because baseline walking is already associated with a high theta power. Immobility could not be observed in a behaving rat after MR-muscimol injection. However, after $20 \mathrm{mg} / \mathrm{kg}$ pentobarbital i.p., MR-muscimol-infused rats showed increased theta power during immobility.

In conclusion, this paper shows that inactivation of various areas in the limbic system enhances effects produced by general anesthetics. Inactivation of some structures affect EEG activation, suggesting that compromising cortical activation may affect awareness and potentiate general anesthesia.

\section{ACKNOWLEDGEMENTS}

This study is supported by CIHR Grant 15685 . We thank B Shen for technical assistance.

\section{REFERENCES}

Altier N, Stewart J (1998). Dopamine receptor antagonist in the nucleus accumbens attenuate analgesia induced by ventral tegmental area substance $\mathrm{P}$ or morphine and by nucleus accumbens amphetamine. J Pharmacol Ther 285: 208-215.

Berendse HW, Groenewegen HJ, Lohman AHM (1992). Compartmental distribution of ventral striatal neurons projecting to the mesencephalon in the rat. J Neurosci 12: 2097-2013.

Berntson GG, Shafi R, Sarter M (2002). Specific contributions of the basal forebrain corticopetal cholinergic system to electroencephalographic activity and sleep/waking behaviour. Eur J Neurosci 16: 2453-2461.

Bland BH, Bland CE, Colom LV, Roth SH, DeClerk S, Dypvik A et al (2003). Effect of halothane on type 2 immobility-related hippocampal theta field activity and theta-on/theta-off cell discharges. Hippocampus 13: 38-47.

Bland BH, Oddie SD (2001). Theta band oscillation and synchrony in the hippocampal formation and associated structures: the case for its role in sensorimotor integration. Behav Brain Res 127: 119-136.

Borhegyi Z, Magloczky Z, Acsady L, Freund TF (1998). The supramammillary nucleus innervates cholinergic and GABAergic neurons in the medial septum-diagonal band of Broca complex. Neuroscience 82: 1053-1065.

Cape EG, Jones BE (2000). Effects of glutamte agonist versus procaine microinjections into the basal forebrain cholinergic cell area upon gamma and theta EEG activity and sleep-wake state. Eur J Neurosci 12: 2166-2184.

Cohen P (1975). Signs and stages of general anesthesia. In: Goodman LS and Gilman A (eds). The Pharamacological Basis of Therapeutics, 5th edn. Macmillan: New York. pp 60-65.

Devor M, Zalkind V (2001). Reversible analgesia, atonia, and loss of consciousness on bilateral intracerebral microinjection of pentobarbital. Pain 94: 101-112.

Dringenberg HC (2000). Serotonergic receptor antagonists alter responses to general anaesthetics in rats. $\mathrm{Br} J$ Anaesth 85: 904-906.

Gasbarri A, Sulli A, Packard MG (1997). The dopaminergic mesencephalic projections to the hippocampal formation in the rat. Prog Neuro-Psychopharma Biol Psychiat 21: 1-22.

Gear RW, Aley KO, Levine JD (1999). Pain-induced analgesia mediated by mesolimbic reward circuits. J Neurosci 19: 7175-7181.

Groenewegen HJ, Vermeulen-Van Der Zee E, Kortschot AT, Witter MP (1987). Organization of the projections from the subiculum to the ventral striatum in the rat. A study using anterograde transport of phaseolus vulgaris leucoagglutinin. Neuroscience 23: 103-120.

Guedel AE (1951). Inhalation Anesthesia: A Fundamental Guide, 2nd edn. Macmillan: New York.

Irifune M, Sato T, Nishikawa T, Masuyama T, Nomoto M, Fukuda $\mathrm{T}$ et al (1997). Hyperlocomotion during recovery from isoflurane anesthesia is associated with increased dopamine turnover in the nucleus accumbens and striatum in mice. Anesthesiology 86: 464-475.

Jasper H (1949). Diffuse projection systems: the integrative action of the thalamic reticular system. Electroencephalogr Clin Neurophysiol 1: 405-419.

Jurkowlaniec E, Tokarski J, Trojniar W (2003). Effect of unilateral ibotenate lesions of the ventral tegmental area on cortical and hippocampal EEG in freely behaving rats. Acta Neurobiol Exp 63: 369-375.

Kinney GG, Kocsis B, Vertes RP (1995). Injections of muscimol into the median raphe nucleus produce hippocampal theta rhythem in the urethane anesthetized rat. Psychopharmacology 120: $244-248$.

Kirk IJ, Oddie SD, Konopacki J, Bland BH (1996). Evidence for differential control of posterior hypothalamic supramammillary, and medial mammillary theta-related cellular discharge by ascending and decending pathways. J Neurosci 16: 5547-5554.

Kirk IJ, McNaughton (1993). Mapping the differential effects of procaine on frequency and amplitude of relicularly elicited hippocampal rhythmical slow activity. Hippocampus 3: 517-526.

Kiss J, Csaki A, Bokor H, Shanabrough M, Leranth C (2000). The supramammillo-hippocampal and supramammillo-septal glutamatergic/aspartatergic projections in the rat: a combined $[3 \mathrm{H}]_{\mathrm{D}-}$ aspartate autoradiographic and immunohistochemical study. Neuroscience 97: 657-669. 
Lee RS, Steffensen SC, Henriksen SJ (2001). Discharge profiles of ventral tegmental area GABA neurons during movement, anesthesia, and the sleep-wake cycle. J Neurosci 21: 1757-1766.

Leranth C, Vertes RP (1999). Median raphe serotonergic innervation of medial septum/diagonal band of broca (MSDB) parvalbumin-containing neurons: possible involvement of the MSDB in the desynchronization of the hippocampal EEG. J Comp Neurol 410: 586-598.

Leung LS (1998). Generation of theta and gamma rhythms in the hippocampus. Neurosci Biobehav Rev 22: 275-290.

Leung LS, Lopes da Silva FH, Wadman WJ (1982). Spectral characteristics of the hippocampal EEG in the freely moving rat. Electroenceph Clin Neurophysiol 54: 203-219.

Ma J, Brudzynski SM, Leung LS (1996). Involvement of the nucleus accumbens-ventral pallidal pathway in postictal behavor induced by a hippocampal afterdischarge. Brain Res 739: 26-35.

Ma J, Shen B, Leung LS (2003). Forebrain structures that participate in general anesthesia. Progr No 374.7 Abstr Soc Neurosci.

Ma J, Shen B, Stewart LS, Herrick IA, Leung LS (2002). The septohippocampal system participates in general anesthesia. J Neurosci 22: 1-6.

Ma Q-P, Han JS (1991). Neurochemical studies on the mesolimbic circuitry of antinociception. Brain Res 566: 95-102.

MacIver MB, Mandema JW, Stanski DR, Bland BH (1996). Thiopental uncouples hippocampal and cortical synchronized electroencephalographic activity. Anesthesiology 84: 1411-1424.

Martin JH (1991). Autoradiographic estimation of the extent of reversible inactivation produced by microinjection of lidocaine and muscimol in the rat. Neurosci Lett 127: 160-164.

Maru E, Takahashi KL, Iwahara S (1979). Effects of median raphe nucleus lesions on hippocampal EEG in the freely moving rat. Brain Res 163: 223-234.

Mogenson GJ, Brudzynski SM, Wu M, Yang CR, Yim CY (1993). From motivation to action: a review of dopaminergic regulation of limbic-nucleus accumbens-ventral pallidum-pedunculopontine nucleus circuits involved in limbic-motor integration. In: Kalivas PW, Barnes CD (eds). Limbic Motor Circuits and Neuropsychiatry. CRC Press: Boca Raton, FL. pp 193-225.

Moruzzi G, Magoun HW (1949). Brain stem reticular formation and activation of the EEG. Electroenceph Clin Neurophysiol 49: 455-473.

Nelson LE, Guo TZ, Saper CB, Franks NP, Maze M (2002). The sedative component of anesthesia is mediated by $\mathrm{GABA}_{\mathrm{A}}$ receptors in an endogenous sleep pathway. Nat Neurosci 5: 979-984.

Paxinos G, Watson C (1986). The Rat Brain in Stereotaxic Coordinates. Academic Press: Sydney.

Rampil IJ (1998). A primer for EEG signal processing in anesthesia. Anesthesiology 89: 980-1002.

Reese NB, Garcia-Rill E, Skinner RD (1995). The pedunculopontine nucleus - auditory input, arousal and pathophysiology. Prog Neurobiol 47: 105-133.

Roizen MF, White PF, Eger EI, Brownstein M (1978). Effects of ablation of serotonin or norepinephrine brain-stem areas on halothane and cyclopropane MACs in rats. Anesthesiology 49: 252-255.
Sainati SM, Lorens SA (1982). Intra-raphe muscimol induced hyperactivity depends on ascending serotonin projections. Pharmacol Biochem Behav 17: 973-986.

Saper CB (1984). Organization of cerebral cortical afferent systems in the rat. I. Magnocellular basal nucleus. J Comp Neurol 222: 313-342.

Semba K (2000). Multiple output patheays of the basal forebrain organization, chemical heterogeneity, and roles in vigilance. Behav Brain Res 115: 117-141.

Shim I, David J, Wirtshafter D (1997). Dissociation of hippocampal serotonin release and locomotor activity following pharmacological manipulations of the median raphe nucleus. Behav Brain Res 89: 191-198.

Steriade M (2003). Neuronal Substrates of Sleep and Epilepsy. Cambridge University Press: Cambridge.

Steriade M, Amzica F (1996). Intracortical and corticothalamic coherency of fast spontaneous oscillations. Proc Natl Acad Sci USA 93: 2533-2538.

Stewart DJ, MacFabe DF, Vanderwolf CH (1984). Cholinergic activation of the electrocorticogram: role of the substantia innominata and effects of atropine and quinuclidinyl benzilate. Brain Res 322: 219-232.

Stumpf C (1965). Drug action on the electrical activity of the hippocampus. Int Rev Neurobiol 8: 77-138.

Swanson LW (1982). The projections of the ventral tegmental area and adjacent regions: a combined fluorescent retrograde tracer and immunofluorescence study in the rat. Brain Res Bull 9: 321-353.

Tung A, Mendelson WB (2004). Anesthesia and sleep. Sleep Med Rev 8: 213-225.

Uchida S, Nakayama $H$, Maehara T, Hirai $N$, Arakaki $H$, Nakamura M et al (2000). Suppression of gamma activity in the human medial temporal lobe by sevoflurane anesthesia. Neuroreport 11: 39-42.

Vanderwolf CH (1969). Hippocampal electrical activity and voluntary movement in the rat. Electroenceph Clin Neurophysiol 26: 407-418.

Vanderwolf CH (1988). Cerebral activity and behavior: control by cholinergic and serotonergic systems. Int Rev Neurobiol 30: 225-340.

Vertes RP, Fortin WJ, Crane AM (1999). Projections of the median raphe nucleus in the rat. J Comp Neurol 407: 555-582.

Vertes RP, Martin GF (1988). Autoradiographic analysis of ascending projections from the pontine and mesencephalic reticular formation and the median raphe nucleus in the rat. J Comp Neurol 275: 511-541.

Wells LT, Rash DK (1999). Emergence 'delirium' after sevofluran anesthesia: a paranoid delusion? Anesth Analg 88: 1308-1310.

Wyss JM, Swanson LW, Cowan WM (1979). Evidence for an input to the molecular layer and the stratum granulosum of the dentate gyrus from the supramammillary region of the hypothalamus. Anat Embryol (Berlin) 156: 165-176.

Yamamoto T, Watanabe S, Oishi R, Ueki S (1979). Effects of midbrain raphe stimulation and lesion on EEG activity in rats. Brain Res Bull 4: 491-495.

Yang CR, Mogenson GJ (1987). Hippocampal signal transmission to the pendunculopontine nucleus and its regulation by the nucleus accumbens: an electrophysiological and behavioral study. Neuroscience 23: 1041-1055. 